\section{Guest Editor's Notes}

In recent years, IASSIST conferences have tended to focus primarily on data documentation, infrastructure, technology, and other technical aspects. All of these topics are crucial to the process. However, the core is the actual data and understanding the subject matter. With the largest number of participants being specialists who help researchers find appropriate data, it was alarming that so little emphasis was placed on a deeper understanding of the subject content and how researchers use the data. A call to arms to focus on the actual data resulted in two sessions collectively titled "Data Reference in Depth" at the 2009 IASSIST Conference, "Social Data and Social Networking: Connecting Social Science Communities Across the Globe". This special issue contains papers that emerged from these two sessions. The presentations have been expanded to further elaborate on data reference.

In most research settings, data librarians are required to be fluent in a range of sources dependent on the needs of their researchers. The data librarian needs to be prepared to move easily between often diverse subject areas. The data librarian has to transition from answering a question on population to trade to health to terrorism to religion and everything in between typically across all geographic boundaries and languages.

This special issue gives readers a sampling of a data librarian's "day in the life" by highlighting a few major subject areas and their primary data sources. Readers will see a few of the particular reference challenges by getting an introduction to some key sources and particular challenges that crop up in a sampling of different areas. In addition, the question "how does providing access to data, as a unique format, affect library reference services?" will be answered.

Kristin Partlo examined how the data reference interview is especially crucial in the provision of research assistance, from the viewpoint of working with undergraduates at a small liberal arts college. The lessons learned have a bearing on research institutions of all sizes and provides a model for getting to the heart of what is really needed. Of particular importance is how to balance providing reference with instructing the researcher to learn from the experience. Partlo shares the data reference worksheet she devised and provides clear examples.

The issue then moves on to major resources available in five distinct subject areas. Amy West provides a detailed analysis of the sources and interfaces for international trade, commodities, prices and production. Walter Giesbrecht follows with a guide to labor looking at both national and international sources as well as the problems of harmonization. Mary Tao provides a timely look at data on the credit crisis. She provides starting points for when a researcher asks for data and/or statistical information on mortgages, credit cards, financial institutions, and other financial crisis-related materials. Both fee-based and free resources are included. Kristi Thompson then turns to the developing world as she looks at survey data on international development. She focuses on survey data for developing countries. She looks at some of the different groups that conduct surveys and make the microdata available. She provides helpful comparisons of the major sources, their sample sizes, geographic and temporal coverage, and access issues. The issue concludes with Michele Hayslett and Lynda Kellam focusing on the major changes that will occur with the 2010 United States Census and American Community Survey. A series of examples illustrate the challenges researchers face with comparability.

The authors and I hope that future conferences and issues of this journal will have a renewed emphasis on the actual data. There are many subject areas to explore and sharing makes us all more knowledgeable. Thanks to Kristi Thompson for taking my ongoing call to arms at conferences and taking the lead to make it materialize into two panels that formed the basis for this double issue. Thanks to these authors for answering the call to arms to talk and to reshape their presentations into full articles about data reference. Thanks again to Kristi for all of her organizational work in coordinating the original speakers into panels and for serving as a speaker, author, and helping to edit this issue.

Bobray Bordelon, Princeton University Library 